\title{
Pronoun Usage as a Measure of Power Personalization: A General Theory with Evidence from the Chinese-Speaking World ${ }^{1}$
}

\author{
Amy H. Liu (D) \\ Department of Government, University of Texas at Austin, Austin, TX, USA \\ E-mail: amy.liu@austin.utexas.edu
}

(Received 7 May 2020; revised 30 November 2020; accepted 7 April 2021; first published online 18 June 2021)

\begin{abstract}
How can the growing personalization of power be identified and measured ex ante? Extant measures in the authoritarian literature have traditionally focused on institutional constraints and more recently on individual behaviour - such as purging opposition members from (and packing allies into) government bodies. This article offers a different strategy that examines leaders' individual rhetoric. It focuses on patterns of pronoun usage for the first person. The author argues that as leaders personalize power, they are less likely to use 'I' (a pronoun linked to credit claiming and blame minimizing) and more likely to use 'we' (the leader speaks for - or with - the populace). To test this argument, the study focuses on all major, scheduled speeches by all chief executives in the entire Chinese-speaking world - that is, China, Singapore and Taiwan - since independence. It finds a robust pattern between first-person pronouns and political constraints. To ensure the results are not driven by the Chinese sample, the rhetoric of four other political leaders is considered: Albania's Hoxha, North Korea's Kim Il Sung, Hungary's Orbán and Ecuador's Correa. The implications of this project suggest that how leaders talk can provide insights into how they perceive their rule.
\end{abstract}

Keywords: Albania; Chinese; Ecuador; Hungary; personalism; pronouns; North Korea

In April 2017, Turkish President Erdoğan narrowly won a referendum. The victory granted him sweeping new powers to further consolidate his rule. Critics quickly pointed to his increasing efforts to compare himself to Atatürk, the founder of modern Turkey (Kingsley 2017). In February 2018, when the Chinese constitution removed the two-term limit for the president thereby allowing Xi to extend his tenure beyond 2022 - pundits immediately drew comparisons to the days of Mao (Wallace 2018). And in early 2020, when the Russian government resigned, there was little doubt among the blindsided country experts that the cabinet reshuffle and proposed national referendum would allow Putin to further consolidate his power (Roth 2020).

In all three cases, there is no question that the power to decide is growing increasingly concentrated in the hands of one individual - that is, personalization. Yet in general, how do we ex ante identify and measure the growing personalization of power? One strategy is to focus on the institutional constraints - that is, who checks and balances the executive (Geddes, Wright and Frantz 2014). However, there are two problems with this method. First, there is the assumption of mutual exclusivity: personalism only happens in the absence of institutions. Yet as we see from the Turkish, Chinese and Russian examples above, personalism can emerge in highly institutionalized environments (see Slater 2003). And conversely, even the most

\footnotetext{
${ }^{1}$ The 'I' to 'we' ratio in the main body of the article is 0.908.

(c) The Author(s), 2021. Published by Cambridge University Press. This is an Open Access article, distributed under the terms of the Creative Commons Attribution licence (http://creativecommons.org/licenses/by/4.0/), which permits unrestricted re-use, distribution, and reproduction in any medium, provided the original work is properly cited.
} 
personalist dictators - such as Indonesia's Sukarno, Libya's Gaddafi or Zaire's Mobutu - do not govern in anarchy. The second problem with the strategy of focusing on institutional constraints is that we risk ex post identification: personalization must have happened in $t-1$ because the dictator is personalist in $t$. Related, we miss the entire population of cases for which there was growing personalization (the process) but personalism (the institution) never manifested (see Meng 2020; Schuler 2021).

An alternative strategy is to examine the dictator's individual behaviours taken - for example, packing, rigging and circumventing (Slater 2003; see Gandhi and Sumner 2020). Yet again there are two concerns about this strategy. First, these actions - individually - are neither necessary nor sufficient. A dictator could employ other actions to personalize. Thus when we do not see packing, for example, we cannot be certain whether this is because the dictator cannot pack, chooses not to pack or does not want to pack. The second concern is that focusing on behaviour risks simultaneous (if not ex post) observation - that is, personalization has already begun to happen (if it has not already happened). We therefore need a strategy that permits ex ante identification.

Here, I propose a third strategy: I focus on a leader's individual rhetoric. Rhetoric is not simply a medium of expression. It is 'a powerful tool' for motivating people to think and behave in particular ways (Breuning and Ishiyama 1998, 6). It reflects 'the idea or set of ideas that legitimi[s]es political practice' (Tulis 2017, 13). Such practices can include the personalization of power. Levitsky and Ziblatt (2018), for example, look at verbal abuse as a way to identify politicians with autocratic tendencies. In this article, I focus on one type of rhetoric: the pattern in pronoun usage. Pronouns - for example, I, you and they - are small words and relatively trivial in sentences. Linguistically, they are closed-class, function words (Carnap 2002). However, it is precisely this perceived insignificance that matters. Speakers use them instinctively; likewise, the audience rarely notices. They reflect the subconscious lens through which the speaker sees their immediate environs. Social psychologists have found patterns in pronoun usage across gender, age, educational attainment and marital status (Pennebaker 2011a, 2011b). Extending this logic, we should be able to observe systematic differences in how leaders talk. Those who personalize power should talk differently from those who do not.

When a policy is successful, all leaders seek to claim credit in an effort to 'generate a belief (Mayhew 1974, 52-53) that they were responsible for some supposed success (Grimmer, Messing and Westwood 2012). Conversely, when a political development is negative, leaders try to avoid taking the blame (Volden 2005). One way to minimize the attention is to clearly demarcate the boundaries of responsibility. Within this boundary, the leader is only responsible for some - if any - of the failures (Schuler 2021). In authoritarian settings - where the fear of rebellion and contention is greater (Cheibub, Gandhi and Vreeland 2009; Gandhi and Przeworski 2007), and where the public finds it more difficult to distinguish the leader's efforts from that of the subordinate (Glazer and Segendorff 2005) - leaders have an incentive to over-claim good results and overemphasize the boundaries to deflect the blame for bad outcomes by using the first-person singular pronoun, 'I' (see Windsor, Dowell and Graesser 2014). In short, constraint makes credit claiming and blame avoiding more pronounced (see Schuler 2021; Volden 2005). Therefore, we should see more use of 'I' when dictators believe they are constrained. For example, when declaring martial law in 1981, Poland's Jaruzelski - in response to mass strikes throughout the country - said, 'I turn to you today as a solider and as the head of the Polish government. $I$ turn to you in matters of supreme importance ... Great is the burden of responsibility that falls on me. It is my duty to take this responsibility ... I announce that today a Military Council of National Salvation has been established. Today at midnight, the Council of State, in accordance with the Constitution, introduced martial law throughout the country. $I$ want everyone to understand the motivates and the aims of our action' (emphasis added). ${ }^{2}$

\footnotetext{
${ }^{2 ‘}$ Martial Law in Poland'. http://soviethistory.msu.edu/1980-2/solidarity-in-poland/solidarity-in-poland-texts/martial-lawin-poland/ (accessed 24 November 2020).
} 
Yet when dictators believe there are few constraints on their personalization of power, I argue they use 'we' more frequently. There are two mechanisms. The first is the exclusive royal 'we': the leader has a divine-like right to speak for the people (see Windsor, Dowell and Graesser 2014). The other is the inclusive group identity 'we': the leader speaks with the people (Andrews-Lee 2019; Waisbord 2011). In his famous last speech in 1989, Romania's Ceausescu remarked, 'We decided to increase minimum pensions from 800 to 900 lei. We decided also that the survivor's pension to be increased by 100 lei. We will also increase social support from about 500 lei to 800 lei... We do everything to ensure the continuous rise of living standards...' (emphasis added). ${ }^{3}$ All leaders talk, and all leaders use pronouns - a minor grammatical instrument that is less likely to be consciously manipulated. As such, by focusing on the pattern usage, we can ex ante identify power personalization.

To test this argument, I focus on the Chinese-speaking world - China, Singapore and Taiwan. I focus on these three states for two reasons. From a linguistic standpoint, Chinese requires the use of pronouns in (almost) every circumstance. Since there is neither verb conjugation nor cases, pronoun identification is very easy. From a theoretical standpoint, all three states have been (and in Taiwan's case, were) long governed by a hegemonic ruling party: the Communist Party in China, the People's Action Party in Singapore and the Nationalist Party (Kuomintang) in Taiwan. All three parties are well noted in the literature for their high levels of institutionalization (Greene 2007). All three states have had at least one strongman who governed for a long period: Mao in China, Lee Kuan Yew in Singapore and Chiang Kai-shek in Taiwan. This variation across an otherwise seemingly constant institution provides the necessary leverage for analysis. In short, I am able to examine within-country and within-person differences.

My sample includes all major scheduled speeches made by the executive in each state from independence to 2016 - or in the Taiwan case, 1996. I measure the distribution of pronoun usage, focusing on the ratio of the first-person singular to the first-person plural. The results suggest that there are greater 'I' to 'we' ratios when institutional constraints are present (and vice versa). Moreover, the ratio drops - whether because there is a decrease in 'I' and/or there is an increase in 'we' - before we observe institutional and behavioural decreases in executive constraints. This suggests that focusing on individual rhetoric is a valid strategy for ex ante identifying and measuring growing personalization.

In the next section, I review the literature on personalism and personalization, citing limitations with extant approaches. I then shift to the theoretical discussion and offer a language-based strategy for ex ante identifying and measuring personalization. In the fourth section, I introduce the research design. I discuss in detail the case selection and the scraped texts. In the fifth section, I evaluate the empirical results - first as an alternative to existing measures and then as a predictive tool. To ensure the results are not specific to Chinese culture, I consider the rhetoric of four other political leaders: Albania's Hoxha, North Korea’s Kim Il Sung, Hungary’s Orbán and Ecuador's Correa.

\section{Personalism: Concept and Measurement}

In her 1999 piece, Geddes offers a typology for classifying dictatorships. In military dictatorships, the other junta members can restrain even the most powerful (Barros 2002); in monarchical dictatorships, the royal family serves as a check (Crystal 1989); and in civilian party dictatorships, the other party members are a constraining mechanism (Greene 2007; Magaloni 2006). Conversely, personalist dictatorships are characterized by the centralization of power in the despot. Prototypes such as Hitler, Pol Pot and Stalin show how at the extreme, few - if any - institutions check the executive's power. In such typologies (also see Weeks 2012; Wright 2008), personalism is conceptualized as the 'rule of one'. In short, there is an absence of (nominal) constraints including that of a strong institutionalized party.

\footnotetext{
${ }^{3}$ http://lybio.net/nicolae-ceausescu-final-speech-1989/news-politics/
} 
Slater (2003; also see Lai and Slater 2006) employs a different conceptualization. Instead of focusing on institutional constraints, he disaggregates despotic power (who decides) from infrastructural power (who executes). He uses this distinction to explain the phenomenon of Malaysia's Mahathir. During his first tenure, Mahathir employed different tactics to personalize his power within the United Malays National Organisation. He purged rivals and appointed loyal allies to top party and government posts (packing); he strategically altered the rules to limit leadership competition (rigging); and he created alternative bodies packed with allies to challenge extant government ministries (circumventing). With this conceptualization, personalization - and ultimately personalism - can manifest in the presence of a strong institutionalized party.

These two competing conceptualizations result in different measurement strategies. The first (for example, Geddes, Wright and Frantz 2014) focuses on institutional constraints. Specifically, how much authority does the executive have in its decision making? Measures such as Polity's xconst look at whether the executive is unlimited at one extreme, or whether they are subject to executive parity - if not outright subordination - at the other extreme. Likewise, Henisz's (2005) polcon focuses on the number of independent government actors, the extent of party alignment and the congruence of preferences within the legislature. The concern with an institutional focus is twofold. First, there is a common assumption of exclusivity - that personalist dictators have no constraints. But empirically, this ignores the population of dictators that personalized power with constraints. Second, the attention is only on the outcome: a dictatorship is considered personalist because the executive behaves like one. But this behaviour does not happen overnight; it is a process - that is, personalization. It involves actions taken by the leader to strip power from others.

This is the foundation of the second strategy - to examine the executive's individual behaviours. Slater (2003) can say with confidence that Mahathir personalized power because he packed, rigged and circumvented. And while these tactics are important, they are neither necessary nor sufficient for personalization. Dictators can employ other tactics such as manipulating term limits and cabinet appointments (Meng 2020). Thus, when we see no evidence of rigging, we are limited in our inference. We cannot determine whether this absence is due to a constrained dictator who cannot rig, whether the dictator can rig but chooses to employ other tactics, or whether the dictator simply does not want to. We can try to identify a set of tactics. Gandhi and Sumner (2020), for example, propose focusing on rules of succession, family influences and cabinet purges. But this heterogeneity of behaviour renders such measurements empirically challenging to identify and code easily across a large sample.

To address these challenges, I propose a third, alternative strategy. I maintain the focus on the individual and not the regime. But I shift the attention from the walk to the talk. Specifically, I examine the executive's individual rhetoric. All executives must talk. Levitsky and Ziblatt (2018), for example, offer a checklist for identifying a budding autocrat - that is, a leader who '(1) rejects, in words or action, the democratic rule of the game, (2) denies the legitimacy of opponents, (3) tolerates or encourages violence, or (4) indicates a willingness to curtail the civil liberties of opponents' (21-22). Whereas these warning signs focus on the what, I contend that we can learn just as much - if not more and sooner - by focusing on the how. By examining how leaders talk, we can cull real-time information about how they perceive their political situation. Rhetoric is the 'amplification or vulgarization of the ideas that produce it' (Tulis 2017, 14). It is the 'avenue to the meaning of alternative constitutional understandings' (Tulis 2017, 14). For example, if a leader perceives they are constrained in some way, they may not pack, rig or circumvent. Alternatively, if they believe there are minimal repercussions, they may adopt such actions. In the next section, I elucidate how speech patterns - specifically, pronoun usage - can ex ante identify and predict personalization. 


\section{Pronouns and Executive Constraints}

Language is more than just a vehicle of communication. It reflects how we see the world (Chen 2013; Liu et al. 2018; Pérez and Tavits 2017). Each language has a set of 'small, stealthy words that can reveal a great deal about [our] personality, thinking style, emotional state and connections with others. These words account for less than 0.1 per cent of [our] vocabulary but make up more than half of the words commonly used' (Pennebaker 2011b, 3). These 'small, stealthy words' include pronouns. Pronouns are function words that have little meaning of their own but serve important grammatical purposes for other words in a sentence (Carnap 2002). How these words are used - even if subconsciously - can reflect an individual's gender, age, educational attainment and marital status. For instance, women more often use 'he', 'she' and 'they' given their greater inclination to talk about people and relationships (Pennebaker 2011a). Conversely, since men tend to be more narcissistic and self-congratulatory, they use 'I' more regularly (see Carey et al. 2015). Likewise, older people are more formal - thus, fewer I's (Pennebaker 2011b). People with less education use more 'I' and 'you' (Pennebaker et al. 2014). And individuals who are happily married more often use 'I' (Simmons, Gordon and Chambless 2005). In short, while these words are small and commonly used - such that we do not necessarily 'hear' them - they suggest how individuals think and see the world in real time.

If how individuals talk reflects their perceived reality, we should be able to observe distinct patterns among leaders. Let us first consider political leaders facing extensive institutional constraints - for example, opposition parties in an elected legislature (Gandhi 2008). Under such conditions, leaders will use their position of authority to be the first and/or final person to say they were the one responsible for the positive outcome - or at least tried to bring about the positive outcome. They want to make sure the relevant audience - whether it is their winning coalition or the larger populace - knows who deserves the credit (Grimmer, Messing and Westwood 2012). And when the outcome is less than positive, the same leader has an incentive to minimize the blame attributed to them. In response, they will aggressively demarcate boundaries, by identifying responsibility for a fixed set of failures (see Schuler 2021; Volden 2005). In authoritarian regimes, these incentives are heightened - in no small part due to a greater fear of rebellion and contention (Gandhi and Przeworski 2007) and because of a lack of transparency (Glazer and Segendorff 2005). One natural and subconscious way to over-claim credit and over-emphasize boundaries to deflect the blame is to use the word 'I'. When it is the singular, first-person pronoun, there is no ambiguity whatsoever as to who is (allegedly) responsible (see Windsor, Dowell and Graesser 2014).

Consider one of Kádár's first speeches to Parliament after the 1956 Hungarian Revolution. In detailing what happened, he notes, ' $I$ cannot discuss in detail...but $I$ should like to say something ... If $I$ view the leadership - and here $I$ have to take the party and the country leadership as one then $I$ have to tell you the following: the leadership of the time can be divided into two groups. [One] resolved that we would correct the mistake, and I am convinced that [we could have eliminated the mistakes] ... I have to tell you that this part of the leadership was in a state of serious confusion during those grave days. Speaking on my own behalf, $I$ can tell you that it was not easy to understand what was happening ... [T] he leadership included another part, and here $I$ have to speak of the Imre Nagy group. I cannot deny that $I$ voted for Imre Nagy to become the Prime Minister. And $I$ shall never deny it, because $I$ did it in the conviction and belief that ... Imre Nagy was still an honest man...' (italicized for emphasis). ${ }^{4}$

Also consider that shortly after becoming General Secretary of the Soviet Communist Party, Andropov noted the importance of economic reform by declaring, ' $I$ would like to forcefully draw your attention to the fact that ... the plan assignments for the first two years of the five-year plan were unfulfilled ... We must wage a more resolute struggle against all violations of the Party,

\footnotetext{
4`Full text of 'János Kádár: Selected Speeches and Interviews' https://archive.org/stream/KadarSpeeches Interviews/Kadar\% 20Speeches\%20Interviews_djvu.txt (accessed 24 November 2020).
} 
state, and labour discipline. I am certain [of] the full support of the Party. [C]omrades, there are many, urgent tasks in the national economy. Needless to say, $I$ have no ready-made recipes for accomplishing them. But the Party and Central Committee will have to find answers. I would like to stress that these questions are of ... importance for the country' ${ }^{5}$ (italicized for emphasis).

In both of these speeches, we see over-claiming of credit (for example, support of the party) and a clear demarcation of responsibility for the bad (for example, voting for Imre Nagy). Both of these mechanisms manifest through the use of the singular first person - for example, 'I' and 'me'. If pronoun usage can reflect perceptions of institutional constraints, I argue the following:

Hypothesis 1 ('I' Hypothesis): The frequency of the first-person singular pronoun increases as executive constraints increase.

Conversely, when political leaders believe there are few constraints on their decision making, their calculations are different. Here, I argue that we should see an increasing use of the firstperson plural - 'we' and 'us'. There are two mechanisms. The first is the exclusive royal 'we'. In these cases, legitimacy is not derived from some formal institution. Instead, it is a right often divine but not always or strictly - accompanied by brute force. The leader gets to act on behalf of the people because God (and/or some group of political elites, such as a privy council) has conferred this authority. As such, when these leaders talk, their rhetoric reflects a collective 'God and I'. In short, the 'we' is said from a position of authority.

For example, consider what the Bruneian sultan said when there was international pushback to the country's 2019 adoption of new sharia laws: 'This is our religious obligation... I am aware that there are many questions... We have given clarification... We are conscious... However, we believe...the merit of the law will be evident... Allah will never bestow upon us laws meant to inflict cruelty... For more than two decades, we have practiced a de facto moratorium on the execution of death penalty...' (emphasis added). ${ }^{6}$

Certainly, the royal 'we' is not used exclusively by monarchs or in reference to the divine. In his 2019 New Year Address, North Korea’s Kim Jong Un remarked, '...2018 was a historic year... our socialist construction entered a new stage thanks for our party... April last year constituted an occasion of pivotal significance in developing our revolution... Our people provided... Thanks to our proactive and positive efforts...the international prestige of our Republic continued to be raised, and in the midst of this, we celebrate...7

The second mechanism is the inclusive group identity 'we', which draws legitimacy from what the people want. This figures prominently among populist leaders - with their unorganized mass support (Weyland 2001), linkages with the legacies of charismatic leaders (Andrews-Lee 2019), and their calls to destroy representative and judicial institutions (Seligson 2007). Their anti-elite rhetoric is characterized by the use of 'us' vs. 'them' (see Waisbord 2011) - and where "I" becomes 'we' as the people are envisioned as a generalized entity subject to the same conditions and frustrations as the individual" (Taggart 2002, 74; quoted in Spruyt, Keppens and Van Droogenbroeck 2016, 338). In short, the 'we' in these cases is used as a collective.

For example, in the middle of Guided Democracy (1960), Indonesia's Sukarno gave a speech in which he remarked, 'Our country should be a country which is full of [industrial enterprises]. We cannot live anymore without electricity, without steam, not very long from now we will not even be able to live anymore without atomic energy. Our ideal is development in that direction' (italicized for emphasis). ${ }^{8}$ Likewise, in 2016 Bolivia's Morales justified his non-constitutional fourth

\footnotetext{
5'Andropov on the Economy'. http://soviethistory.msu.edu/1980-2/our-little-father/our-little-father-texts/andropov-onthe-economy/ (accessed 24 November 2020).

6‘05.05.19 SPCO Clarified'. http://www.pmo.gov.bn/Lists/News/DispForm.aspx?ID=1188 (accessed 7 May 2020).

${ }^{7}$ Kim Jong Un's 2019 New Year Address'. https://www.ncnk.org/resources/publications/ kimjongun_2019_newyearaddress.pdf/file_view (accessed 7 May 2020).

${ }^{8 ‘}$ National Electricity Day’. http://www.technologystories.org/national-electricity-day/ (accessed 7 May 2020).
} 
term by stating, '[This] is our experience. Here we never had political stability... In order to dominate $u s$... they divided $u s$ politically so they could take our natural resources... When we fought for deep democracy, [critics] would say we were guerrillas, terrorists' (emphasis added). ${ }^{9}$

Whether it is an exclusive royal 'we' or an inclusive collective identity 'we', I contend that the first-person plural pronoun creeps increasingly into a leader's rhetoric when they believe there are minimal obstacles to getting what they want. The following hypothesis summarizes this argument:

Hypothesis 2 ('We' Hypothesis): The frequency of the first-person plural pronoun increases as executive constraints decrease.

\section{Research Design}

To test the argument, I examine executive speeches made in China, Singapore and Taiwan - the three states in which Mandarin Chinese is an (if not the) official language and where the majority of the population is Han Chinese ( $\mathrm{Hu}$ and Liu 2020). Every executive has been a male ethnic Han. ${ }^{10}$ This design allows me to hold constant latent ethnic and gender effects while examining within-country and within-person differences. I selected these cases for two reasons.

The first relates to linguistics. Like English, Chinese is a subject-verb-object language - for example, 'I eat breakfast tacos' ('我吃蛋餅'). The Chinese language requires a subject - for example, a pronoun - to be explicitly stated. Just as it is not grammatically acceptable to say 'eat breakfast tacos' in English (assuming it is not meant to be an imperative), it is not correct to say '吃蛋餅'. The subject - in this case, ' $\mathrm{I}$ ' or '我” - is necessary. In Chinese, subjects are obligatory because verbs are not conjugated (see Huang 1989). This is in stark contrast to null-subject languages such as Russian and Spanish, in which verb conjugations indicate whether the subject is first, second or third person and whether it is singular or plural (see Chomsky 1980). Thus the sentence 'I eat breakfast tacos' in Spanish does not need the pronoun; it can simply be 'Como tacos de desayuno'. If the analysis is about the frequency of pronouns, it is much easier when every subject is explicitly stated.

Additionally, the Chinese language has no cases. Whether the pronoun is a subject, object or possessive, the pronoun is the same. For example, the sentence 'He gives his taco to him' has three pronouns. Yet because English has cases, we must adjust each pronoun accordingly. Conversely, the same sentence in Chinese would employ the same pronoun 他 (pronounced $t a$ ) throughout the entire sentence: $t a$ gives $t a$ 's taco to $t a$. Here, the pronoun '他' captures all cases of the thirdperson singular. This linguistic feature substantially simplifies the data scraping and ensures that I can identify all possible instances of pronoun usage.

The second reason for focusing on the Chinese-speaking world is theoretical. All three states have been - or in Taiwan's case, was - long governed by a highly institutionalized hegemonic party. In China, the Communist Party (CCP) remains supreme. Likewise, in Singapore, the People's Action Party has never lost power. And while the Nationalist Party in Taiwan (KMT - Kuomintang) is no longer in office, during the authoritarian heyday the party was strong.

At the same time, in each state, there have been substantial variations in the extent of personalization. In China, Mao's unrivalled grip on power culminated with the Cultural Revolution. Deng, another strongman, followed, although he showed more restraint than his predecessor. The next two Chinese leaders, Jiang and $\mathrm{Hu}$, were both constrained to some degree and both stepped down after their two terms ended. Xi's current deviation from this decades-long established pattern has concerned pundits.

\footnotetext{
${ }^{9}$ "Morales: 'It is not the people of Evo, it is the power of the people". https://www.theguardian. com/world/2016/feb/20/ evo-morales-bolivian-president-fourth-term-referendum (accessed 7 May 2020).

${ }^{10}$ The first and only female ethnic Han executive to date is Taiwan's Tsai Ing-wen. She was first elected in in 2016 and subsequently re-elected in 2020 - both during the democratic period.
} 
Table 1. Tenure of leaders in the Chinese-speaking world

\begin{tabular}{lll}
\hline China & \multicolumn{1}{c}{ Singapore } & \multicolumn{1}{c}{ Taiwan } \\
\hline Mao Zedong (1949-76) & Lee Kuan Yew (1965-90) & Chiang Kai-shek (1949-75) \\
Deng Xiaoping (1978-92) & Goh Chok Tong (1990-04) & Chiang Ching-kuo (1978-88) \\
Jiang Zemin (1993-02) & Lee Hsien Loong (2004-) & Lee Teng-hui (1988-00) \\
Hu Jintao (2002-11) & & Chen Shui-bian $(2000-08)^{\dagger}$ \\
Xi Jinping (2012-) & & Ma Ying-jeou (2008-16) \\
& & ${\text { Tsai Ing-wen }(2016-)^{\dagger}}^{\dagger}$ \\
\hline
\end{tabular}

*Election in 1996

†Democratic regime

In Singapore, Lee Kuan Yew negotiated his country's independence from the British by way of a Malaysian merger (1963-1965). His tenure continued beyond the early/mid-1980s when many of his fellow first-generation party colleagues were asked to leave - if not pushed out of - politics to make room for the second-generation cadres. In 1990, Lee Kuan Yew handed the baton to his protégé Goh, who held the top office until 2004. In that year, Lee Kuan Yew's oldest son Lee Hsien Long assumed the premiership. And until 2011 the elder Lee remained in the cabinet, first as a senior minister (19902004) and then as minister mentor (2004-2011). Goh - who had also assumed the title of senior minister in 2004 - resigned from his cabinet post in 2011. And in spite of a recent public family squabble when his siblings alleged power abuse, ${ }^{11}$ the junior Lee remains Singapore's chief executive today.

It was during Chiang Kai-shek's leadership that the KMT retreated from mainland China to Taiwan, where he subsequently ruled with an authoritarian grip. During his tenure (through 1975), tensions with Mao and the CCP escalated against the backdrop of the Cold War. It was also during this period that Taiwan was expelled from the United Nations (1971). And while his son Chiang Ching-kuo continued the KMT's authoritarian rule, there was increasing liberalization - mostly in the social realm. Credit for political liberalization ultimately goes to Lee Teng-hui. Upon assuming the office of the presidency in 1988, Lee Teng-hui navigated the country's transition to democracy, including the 1996 election, which he won. Table 1 identifies each executive's tenure in all three states.

The dataset includes all major scheduled speeches that are delivered annually and regularly: Gregorian New Year, Chinese New Year and National Day (1 October in China, 9 August in Singapore and 10 October in Taiwan, respectively). I limit the sample to these speeches to ensure comparability across years and states. Moreover, I wanted to avoid speeches being endogenous to some exogenous security crisis - for example, the SARS outbreak in China, the East Asian Crisis in Singapore or the Chinese missile launch in Taiwan. Admittedly, these scheduled speeches are the least representative of how executives naturally talk. In fact, they are scripted by speech writers. But the general tone should still reflect to some degree the perceived constraints. After all, the leader still gives the final approval. Thus, whatever effects I find are essentially the floor.

The dataset includes a total of 322 speeches. I run all analyses on the Chinese-language sample using the Linguistic Inquiry and Word Count (LIWC) package. LIWC is appropriate given its attention to pronouns and a built-in Chinese dictionary (Pennebaker et al. 2015). To ensure validity and replicability, I also pivot the texts into English using Google Translate. Admittedly, the translations are not always sensible. But what matters is that the pronoun is never lost or incorrectly translated.

The unit of analysis is country-year-executive. I do not use speech as the unit because the ultimate dependent variable of interest - power personalization - is only reported annually (more below). But since executive terms do not always coincide with the Gregorian calendar, some years have two executives. Here, I am careful to differentiate between the multiple leaders.

\footnotetext{
${ }^{11}$ 'Singapore PM Lee Hsien Loong family feud erupts again'. http://www.bbc.com/news/world-asia-40270152 (accessed 7 May 2020).
} 
(a) Mao Zedong

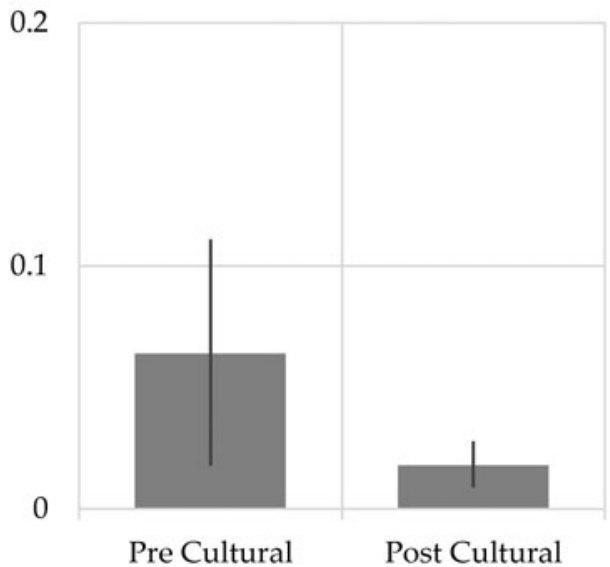

(b) Lee Teng-hui

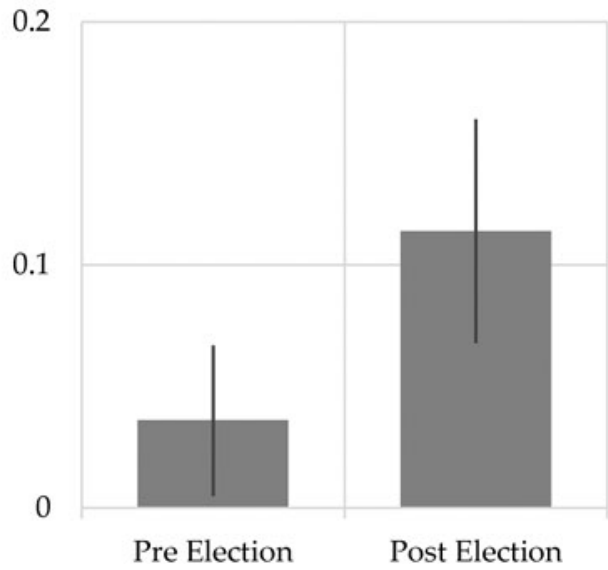

Figure 1. Proof of concept: China's Mao vs. Taiwan's Lee Teng-hui

The key independent variable is the frequency of I's and we's. However, it is not the absolute frequency of each pronoun that matters. They can both increase when a leader simply talks more. I need to consider their relative frequency. Here, we see an advantage of the Chinese language: since subjects are grammatically required, I can identify whether - and when - the leader uses the first-person singular versus the plural. And by focusing on the ratio between the ' $\mathrm{I}$ ' and the 'we', I can directly test my hypotheses. Specifically, I predict the following:

Prediction: As the ratio of 'I' to 'we' decreases, institutional constraints facing executive decision making also decrease.

\section{Empirical Evidence}

For proof of concept, I first look at the 'I' to 'we' ratios for two specific leaders - both extreme examples. We should see big differences in how the leader used the first-person pronouns. The first is China's Mao. What China experienced during the Cultural Revolution was undoubtedly Mao personalizing power. If my pronoun-usage measurement is valid, we should see a large drop in the 'I' to 'we' ratio from before (-1965) to during and after (1966-) the Cultural Revolution. Figure 1(a) plots the average ratio for the two periods. The ratio is less than 1 in both periods - indicating the use of fewer I's than we's. But what is important is the difference in ratio. We see a threefold decline in the use of ' $\mathrm{I}$ ' from 0.06 to 0.02 , accompanied by an increasing use of 'we'. In stark contrast to Mao is Taiwan's Lee Teng-hui, under whose leadership Taiwan transitioned from post-martial law to democracy. Politically, this is the exact opposite of what we see in China with the Cultural Revolution. In this regard, I expect the ratio of 'I' to 'we' to increase over time. And indeed, it jumps from 0.04 to 0.11 (see Figure 1b). These two figures not only serve as proof of concept, but they also suggest that while individuals may be predisposed to using 'I' more (or less) than 'we', the changes over time - in either direction - suggest that there is a situational factor to consider.

\section{Comparing to Extant Measures of Personalization}

Having established the baseline proof of concept, I now examine the average 'I' to 'we' ratio across different coding schemes. I first direct my attention to those looking at institutional constraints - 
(a) Polity: xconst

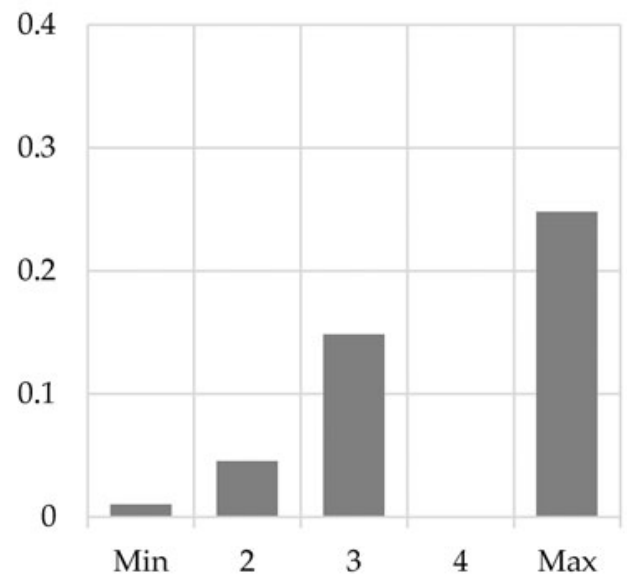

(c) Lai-Slater: bossism

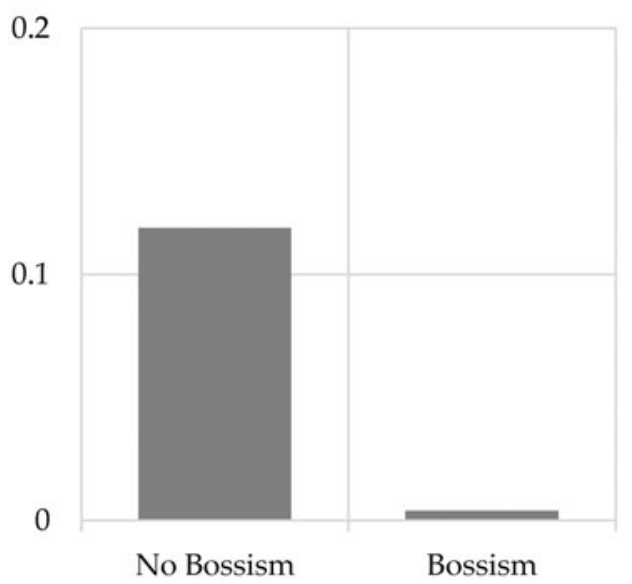

(b) Henisz: polcon

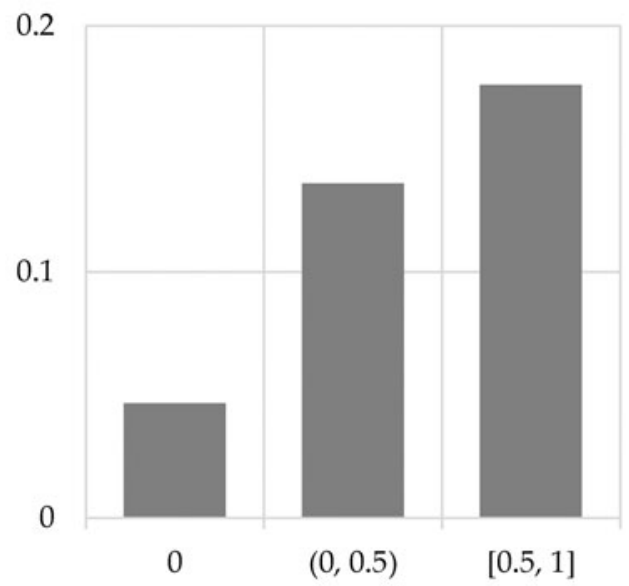

(d) Gandhi-Sumner: consolidation

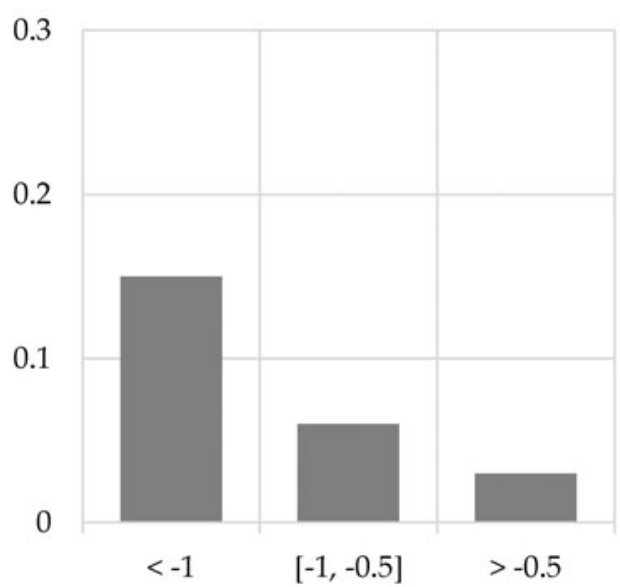

Figure 2. Ratio of 'l' to 'we' across extant measures

that is, who checks and balances the executive. Here, one of the most common measures is Geddes, Wright and Frantz (2014). Dictatorships are classified categorically as monarchies, personalist, military, party and/or oligarchs. But as it turns out, all dictatorships in the Chinese-speaking world are coded as 'party based'. No single country-year observation is considered 'personalist' not even Mao during the Cultural Revolution. Unfortunately, this lack of institutional variation makes it impossible to compare my pronoun-usage measure.

We do see variations with the other measures, such as Polity's xconst. This measure focuses on the 'extent of institutionalised constraints on the decision-making powers of the chief executives' (Dataset Users' Manual, 23). The variable ranges from unlimited authority (1) to slight/moderate limitations (3) to substantial limitations (5) to executive parity or subordination (7), with intermediate categories in between. Among dictatorships in the Chinese-speaking world, we see a range from a minimum of 1 (China 1966-1968) to the authoritarian maximum of 5 (Taiwan 1992-1995). Figure 2a reports the average 'I' to 'we' ratios across each level of xconst. We see a general upward trend as the executive constraints increase. When the executive has unlimited 
authority, the ratio of 'I' to 'we' is 0.01 , suggesting very few uses of the first-person singular. Put differently, we see one first-person singular for one hundred first-person plurals! From there, the number increases rapidly, where at slight-moderate limitations (3), we see a ratio of 0.15 . And at the maximum value, we see one singular for every four plurals. These differences are significant. Note that there are no observations at $x$ const $=4$.

I also consider Henisz' polcon measure, which focuses on 'the extent to which any one political actor or the replacement for any one actor - e.g., the executive or a chamber of the legislature - is constrained in his or her choice of future policies' (Henisz 2005, 10) - that is, the number of independent actors, the extent of party alignment and the congruence of preferences within the legislature. The rationale is that fewer independent actors, more party alignment and/or more preference congruence indicate weaker constraints. The final measure ranges from 0 (most hazardous) to 1 (most constrained). Figure $2 \mathrm{~b}$ plots the average 'I' to 'we' ratios across three values of polcon. When polcon is at a value of 0 - constituting more than half of the observations in the sample - we see a ratio of 0.05 . This ratio almost triples $(0.13)$ once we introduce minimal constraints. And when there are extensive constraints, this ratio increases to almost one 'I' for every five 'we'.

In contrast to those focusing on institutional constraints, other measures look at individual behaviour. Lai and Slater (2006), for example, measure for bossism - an arrangement in which a single despot makes the decisions, but has a party to execute these decisions. In short, the focus is on the leader's actions: are they packing, rigging and circumventing? And while this is a dichotomous variable, there is variation across the Chinese-speaking world, even if the measure only goes up to 1992. Theoretically, we would expect bossism to have lower levels of 'I' to 'we' ratio. Indeed, the empirics confirm this: a boss uses the first-person singular once per one hundred first-person plurals - a statistic that is consistent with previous measures. But when the dictator is not a boss, this ratio increases to 0.27 (see Figure 2c).

Gandhi and Sumner (2020) also focus on dictator behaviour towards personnel and institutions. Using item response theory, they identify the extent of power consolidation. These actions include term limit changes, military purges, civilian purges, and cabinet changes. The latent degree of consolidation is a continuous measure, where higher values indicate more consolidation. In the Chinese-speaking sample, 95 per cent of the measures fall between -1.58 and -0.63 . To assess, I look at the 'I' to 'we' ratio above and below this mean $(-1.02)$. The results in Figure $2 \mathrm{~d}$ show that as consolidation increases, the ratio drops from 0.15 to 0.05 . And in fact, if we focus only on the extreme degrees of consolidation $(>0.50)$, we see that the ratio drops to 0.02 - a number on par with Lai and Slater's bossism measure. In short, we find that patterns of pronoun usage can be used to identify personalization. In the next section I explore whether pronoun usage can be used to predict personalization.

\section{Predicting Future Personalization}

Having established that the 'I' to 'we' ratio is lower when there is more personalization, this raises a follow-up question: when we see decreasing levels of 'I' to 'we' ratios, does this suggest increasing future personalization? To test whether this is the case, I estimate the models with leader and country fixed effects to control for unobserved heterogeneity that may be associated with the individual or the polity. I also use year fixed effects to capture any over-time changes and include a control for the proportion of other pronouns (second person and third person). Finally, I include a measure for the number of years the leader has been in office (logged). A counter here serves four purposes: (1) it accounts for heightened external security threats early in a leader's tenure, which could affect how he talks independent of institutional constraints (Wu and Wolford 2018); (2) it controls for how most leaders need time to personalize power; (3) it allows for increasing familiarity in interactions that leaders may have with others; and (4) it serves as a proxy for age all of which can manifest in how they talk. 


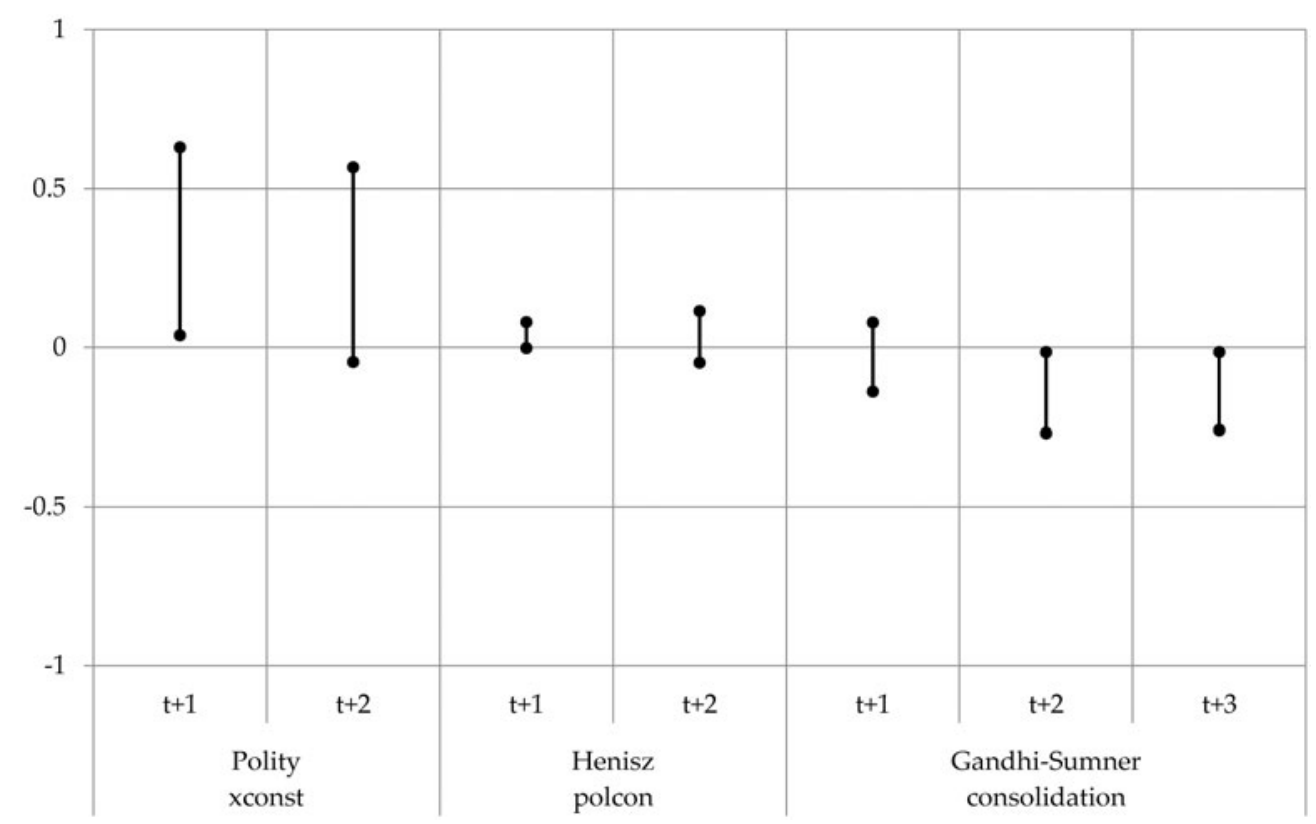

Figure 3. Marginal effects of ' $l$ ' to 'we' ratio on personalization

Note: Models estimated with leader, country, and year fixed effects. Other controls include the proportion of second person and third person pronouns. No model estimated for Geddes, Wright and Frantz personalism and Lai and Slater bossism.

The results suggest that we can ex ante identify growing personalization (see Figure 3). Note that I am not able to estimate a model for either the Geddes, Wright and Frantz personalist variable or the Lai and Slater bossism variable due to insufficient over-time variation. In the first set of models, I look at Polity's xconst. I consider the effects of the 'I' to 'we' ratio on the following year's level of institutionalized constraints. We see that the coefficient is signed in the correct direction and significant at the 0.05 level $(t$ value $=2.21)$. A shift from a ratio of 0.53 (sample mean plus one standard deviation) - that is, one 'I' for every two we's - to 0.23 (sample mean) can decrease next year's executive constraints by 0.10 . The effects are still significant - with a smaller magnitude - if we look at two years out: the same shift can drop executive constraints by 0.08 . Considering that xconst is on a seven-point scale, this is not trivial. Moreover, if we flipped the model to predict the 'I' to 'we' ratio, the coefficient for the lagged xconst is neither significant nor in the correct direction (results not reported; available upon request).

We see a similar story when we shift the dependent variable to Henisz's polcon. Again, I look at the effects of the 'I' to 'we' ratio on next year's measure. Here, the coefficients are in the right direction, although the effect magnitude is much smaller. The same shift from 0.53 to 0.23 in the 'I' to 'we' ratio drops political constraint levels by 0.01 one year out - and two years out, although this latter effect is not statistically significant.

If we conceptualized personalization based on individual behaviour - using Gandhi and Sumner's consolidation measure - the results still hold, with one caveat. While the rhetoric in year $t$ does not predict behaviour in year $t+1$, it does for years $t+2$ and $t+3$. A drop in the 'I' to 'we' ratio from one to two (0.53) to one to four (0.23) increases the latent degree of consolidation by 0.04 . While this magnitude may not seem large, it is statistically significant. Interestingly, if we flip the model to assess whether consolidating behaviour from two years (or three years) ago predicts individual rhetoric in the current year, the coefficient is not significant by any conventional measure (results not reported; available upon request). There are two possible explanations. The first is that - as I argue in this article - rhetoric precedes the 
behaviour. When the use of 'I' drops in relation to the 'we', this suggests possible forthcoming institutional or personnel changes. The second is that rhetoric and behaviour are two measures tapping at the same underlying concept - that is, increasing personalization - which can (but do not always) overlap.

\section{Generalizing beyond the Chinese-Speaking World}

The results thus far demonstrate the merit of looking at individual rhetoric for identifying personalization. They do, however, call into question whether the purported effects are specific to the Chinese language, if not the culture (see $\mathrm{Na}$ and Choi 2009). In this section, I assess this claim by shifting the attention to four other political leaders. Whether some of these individuals are considered personalist is not the point here; rather, I seek to demonstrate that we see a shift in the use of 'I' to 'we' ratio among those known for personalizing (or having personalized) power. Note that I picked these four leaders based on two considerations. One was practicality - that is, their speeches were easily accessible for scraping and analysing. The other was motivated by an intent to consider a diversity of languages.

\section{From Party to Personalist: Hoxha and Kim II Sung}

Albania's Hoxha (1941-1985) and North Korea's Kim Il Sung (1948-1994) both came to powerafter removing several communist comrades - with the support of a party apparatus. And in the early years, both dictators aligned with the Soviet Union. But following Stalin's death, the two countries diverged. As Hoxha grew critical of Khrushchev's policies, his disdain resulted in him siding with China during the Sino-Soviet split. But with Mao's death in 1976, Hoxha pursued an aggressive isolationist policy. There was a constant fear of an attack from neighbouring Italy or Yugoslavia - if not the Soviet Union or the United States (Fevziu 2016). By contrast, for North Korea, Kim Il Sung faced joint Sino-Soviet efforts to depose him in favour of a pro-Chinese faction (Chung 1978; Kim and Zagoria 1975). After resisting these challenges (the August 1956 Faction Incident), Kim further personalized his power and held onto it until his death. Even after his death, the cult of personality reigned supreme: the 2012 constitution designated him 'Eternal President'. Given this discussion, I predict the following:

Hoxha Prediction: Enver Hoxha's ratio of 'I' to 'we' is lower after Mao Zedong's death in 1976.

Kim Prediction: Kim Il Sung's ratio of 'I' to 'we' is lower after the August 1956 Faction Incident.

To test the Hoxha prediction, I scrape the speeches from the six volumes of Enver Hoxha: Selected Works, published by the Central Committee of the Albanian Labour Party. All speeches have already been translated into English. It is important to recognize that many of these speeches were annual speeches to the party (that is, highly scripted). Combined with the relatively small sample $(n=219)$, we can think of these results as a floor. Figure 4 a confirms this: prior to the isolation period, Hoxha talked more in the first-person singular than after. After Mao died and Albania entered an isolation period, there was an uptick in the use of the first-person plural. However, the difference in the average ratio is not statistically significant $(p<0.14)$.

To test Kim Il Sung's pronoun usage, I draw on the texts - from telegrammed communiqués to conversation records to public speeches - posted on the Wilson Center Digital Archives. In all, there were 249 such documents spanning his entire tenure. The majority of these documents have been translated into English (the exceptions are in Russian). Likewise, with such a small sample, I am cautiously optimistic about finding a significant difference after 1956. The results in Figure $4 \mathrm{~b}$ show that not only do we see a difference, but that this difference is significant at the $\mathrm{p}<0.10$ 
(a) Albania: Hoxha

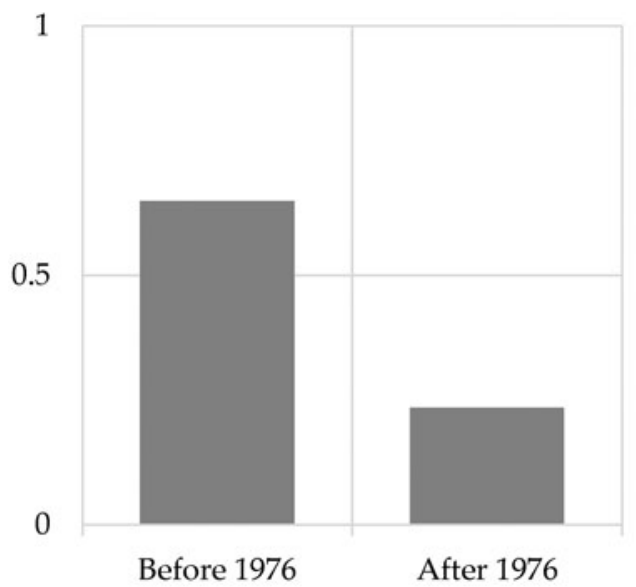

(c) Hungary: Orbán

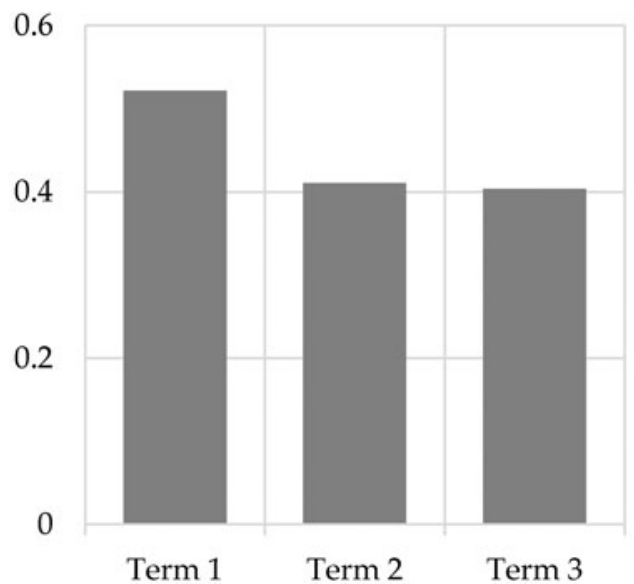

(b) North Korea: Kim Il Sung

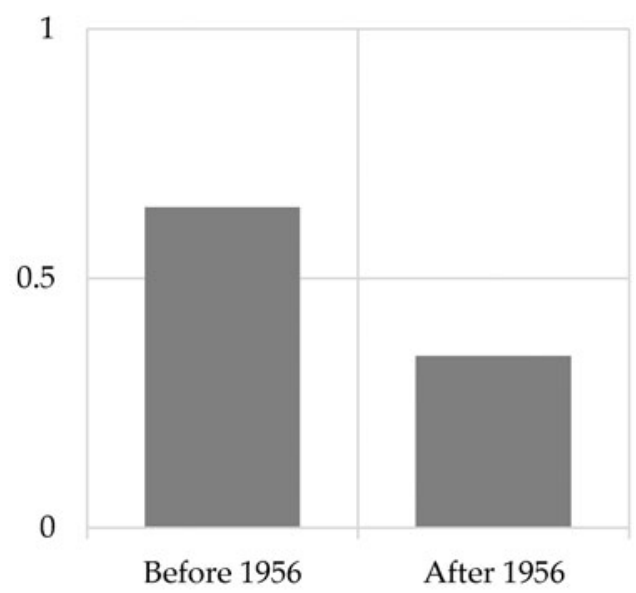

(d) Ecudaor: Correa

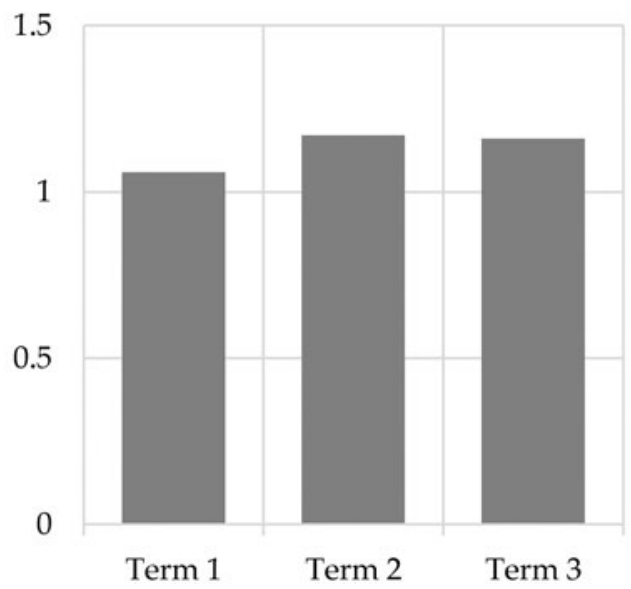

Figure 4. Ratio of 'l' to 'we' across non-Chinese leaders

level. Before the Sino-Soviet efforts to remove him, Kim Il Sung's 'I' to 'we' ratio was 0.65. After 1956 , this figure dropped to 0.34 .

\section{From Democrat to Populist: Viktor Orbán}

Admittedly, Hoxha and Kim Il Sung are two examples of extreme personalist leaders. If individual rhetoric can indicate growing personalization, we should see this in leaders who have effectively undermined many of the institutional constraints but are not yet personalist. Here, I look at Hungary's Orbán - who went from being a champion of democracy in 1989 to becoming a 'headache' (Simon, Cook and Clarke 2018). His first stint as prime minister was in 1998 when his party won a plurality of seats. He subsequently lost re-election in 2002 and remained in the opposition for the next 8 years. In 2010, Orbán and his party returned to power with a supermajority mandate - the first time in post-communist Hungary. Orbán has used this mandate to slowly hollow out the state - from harassing non-governmental organizations to chasing away critical media, 
from building walls to reinstating the death penalty - rendering it effectively a mafia state (Bozóki 2015; Magyar 2016). He is currently serving a third consecutive term. Given this discussion, I predict the following effect:

Orbán Prediction: Viktor Orbán's ratio of 'I' to 'we' is lower in the later terms than in his first (2010-2014).

The relevant corpus is from the Hungarian Government's website, which lists Orbán's speeches back to 2010. The speeches have all been translated into English (and in a number of cases, German and French). I identified a total of more than 700 speeches. The results can be found in Figure 4c. Consistent with ex ante predictions, we see a small - but nonetheless significant - drop in the 'I' to 'we' ratio from over 0.50 in the first term (2010-2014) to just above 0.40 in the second (2014-2018) and current (2018-) terms. The corpus includes one month of speeches between the first COVID-19 cases detected in Hungary and parliament granting decree power to Orbán (per state of emergency). In this period, his 'I' to 'we' ratio drops by 8 percentage points.

\section{From Populist to Populist: Rafael Correa}

Ecuador's Rafael Correa (2007-2017) came to power as part of the 'left turn' populist wave in Latin America (Baker and Greene 2011). Throughout his three terms, he was consistent with his semi-authoritarian, economically populist, socially conservative and anti-American (pro-Chinese) policies (Cupery 2011). Datasets on populism - for example, Kenny (2020) and Rhodes-Purdy and Madrid (2020) - show very little change (if any) for Correa across his three terms. Here, this non-variation over time offers a unique test for my theory. If individual rhetoric - that is, pronoun usage - reflects how a political leader sees their surroundings, and if the surroundings are supposedly constant, then we should see little change in how they talk. Specifically, I expect the following effect:

Correa Prediction: Rafael Correa's ratio of 'I' to 'we' is the same across all three terms.

To test this null prediction, I used data from Cupery (2011), which includes all speeches by Correa minus the last nine months. To the best of my knowledge, this is the most comprehensive corpus. In all, there are more than 640 articles across the three terms. Figure $4 \mathrm{~d}$ illustrates that the ratio of ' $\mathrm{I}$ ' to 'we' remained steady across all three terms (1.06, 1.17 and 1.16). Compared to Albania's Hoxha, North Korea's Kim Il Sung and Hungary's Orbán, Correa used the first-person plural much more often. There are several possible explanations for this. First, it could be about the individual: Correa just naturally used 'we' more than his counterparts. Secondly, it could be about the corpus. The Hoxha, Kim and Orbán corpora were all translated semantically by a government agency into English, while the Correa corpus was in Spanish. Thirdly, it could be about the language. Spanish is the only major Indo-European language considered in this article (note: while Albanian is an Indo-European language, it is an isolated language family). There could be some cultural feature. And last, it could be about the political landscape: the steady state of populism in Ecuador allowed Correa to always talk confidently, often using 'we'.

\section{Conclusion}

The results in this article suggest that there is an alternative ex ante strategy for measuring personalization that focuses neither on institutional constraints nor on individual behaviour. Instead, it looks at the individual rhetoric espoused by the executive. Focusing on all major, scheduled speeches made by leaders in China, Singapore and Taiwan, I find evidence of a distinct pattern with pronoun usage. Counterintuitively, as leaders personalize, they use fewer I's but more we's. 
The use of the first-person singular is associated with the need to claim credit for good outcomes when there are multiple proverbial chefs in the kitchen - and to overemphasize boundaries to minimize the blame when something bad happens. However, with personalization, the use of the first-person plural increases. There are two possible mechanisms. One is the exclusive royal 'we', where the leader speaks with some divine-like authority for the people. The other is the inclusive group identity 'we', where the leader speaks with the people. This pattern is by no means specific to the Chinese language or culture; I find similar trends with Albania's Hoxha, North Korea's Kim Il Sung, Hungary's Orbán and Ecuador's Correa.

By focusing on individual rhetoric, this strategy addresses two concerns with the literature. First, if we focus only on personalist leaders - that is, those who have no institutional constraints - we miss the universe of cases in which a leader tried to personalize but did not, for whatever reason. And this is by no means only an empirical concern. It is also a normative one. We want to be able to identify ex ante when a leader starts to - or attempts to - personalize power. But if we assess behaviour - whether it is packing, rigging or circumventing - there is no guarantee that the menu of actions is exhaustive or sufficient. We may miss ongoing cases of personalization and not identify it until after the fact. Moreover, we risk ignoring the cases of leaders who tried to personalize but failed. Thus, by examining how an individual speaks and focusing on what Pennebaker (2011a) calls the 'small, stealthy words', this article offers an additional ex ante approach to identification and prediction. The fact that these analyses - with the possible exception of Orbán - are based on formal, pre-scripted speeches is insightful. If country specialists are able to observe in detail how a leader talks informally - from a press conference to a tweet - we should see even more pronounced effects of 'I' and 'we' usage.

There are at least three avenues of future research involving a focus on patterns of pronoun usage. The first is to shift attention away from domestic institutional constraints and to focus instead on how external security threats affect pronoun usage. It is possible that even in the absence of opposition parties and competitive elections, a dictator may still have to confront the threat of a military invasion from a neighbouring state, which could affect how the dictator speaks. On the one hand, this context of insecurity may motivate the dictator to use more 'I'. On the other hand, as the threat is against the whole country (inter-state) rather than a domestic (intra-state) threat, the dictator may use 'we' more naturally.

The second avenue of research is to shift the pronoun focus from the first to the third person in the case of a global crisis. When there is an external crisis - whether it is financial, humanitarian or epidemiological - there is a need to assign blame to some third party. As Hungary's COVID-19 numbers increased, there was a 10 per cent drop in Orbán's 'I' to 'we' ratio and a doubling in the use of the third person - culminating in what the Washington Post titled, 'Coronavirus kills its first democracy' (Tharoor 2020). And this is by no means specific to either Hungary or COVID-19: from India's Narendra Modi (Krishnan 2020) to the Philippines' Rodrigo Duterte (McCarthy 2020), there is increasing commentary on the personalization of power in supposed democracies (Gebrekidan 2020).

The third avenue of research would be to pivot the focus away from the government to the opposition. When an individual is challenging the government, they must rally the opposition. To do so, they must speak for the masses when they articulate demands. If this is the case, we should see greater use of the first-person plural. But once they enter office, we should see a shift to the first-person singular. A preliminary analysis (albeit on a limited sample) of Orbán's speeches - including those from 1989 against the Communist Party and during the 2002-2010 period when he was in the opposition - shows a high frequency of 'we'.

Data availability statement. All replication material (data and instructions) can be found on Harvard Dataverse at: https:// doi.org/10.7910/DVN/FK6N8R.

Acknowledgements. A previous version of this article was presented at the 2016 Taiwan in the Realm of East Asia Conference, Wake Forest University (organizer: We-chin Lee); 2018 Western Political Science Association Annual 
Conference, San Francisco (discussant: Kai Ostwald); 2018 Text as Data Conference, University of Washington (discussant: Arthur Spirling); 2019 Southern Political Science Association Annual Conference, Austin (discussants: Jen Gandhi and Dan Slater); and 2019 Texas Comparative Circle Conference, Texas A\&M University (organizers: José Cheibub and Diana O’Brien). Many thanks to TJ Cheng, Keith Chew, Iza Ding, Roman Hlatky, John Hsieh, Chien-Pin Li, Tse-min Lin, Raúl Madrid, Anne Meng, Ariel Pitre Young, Eion Power, Nico Ravanilla, Cheryl Schonhardt-Bailey, Paul Schuler, Leslie Schwindt-Bayer, Sam Selsky, Sarah Shair-Rosenfield, Katy Smith, Zeynep Somer-Topcu, Randy Stevenson, TY Wang, Chun-Ying $\mathrm{Wu}$ and two anonymous reviewers for their comments. This article would not be possible without Titus Chen, David Cupery, Jeff Jacobs and Wenhui Yang, who helped identify relevant texts.

Financial support. The author received no financial support for the research, authorship, and/or publication of this article.

Competing interests. The author declares no potential conflicts of interest with respect to the research, authorship, and/or publication of this article.

\section{References}

Andrews-Lee C (2019) The revival of charisma: experimental evidence from Argentina and Venezuela. Comparative Political Studies 52(5), 687-719.

Baker A and Greene KF (2011) The Latin American left's mandate: free-market policies and issue voting in new democracies. World Politics 63(1), 43-77.

Barros RJ (2002) Constitutionalism and Dictatorship: Pinochet, the Junta, and the 1980 Constitution. New York: Cambridge University Press.

Bozóki A (2015) Broken democracy, predatory state, and nationalist populism. In Krasztev P and Van Til J (eds), The Hungarian Patient. Budapest: Central European University Press, 3-36

Breuning M and Ishiyama JT (1998) The rhetoric of nationalism. Political Communication 15(1), 5-26.

Carey AL et al. (2015) Narcissism and the use of personal pronouns revisited. Journal of Personality and Social Psychology 109(3), e1-e15.

Carnap R (2002) The Logical Syntax of Language. Chicago, IL: Open Court Publishing.

Cheibub JA, Gandhi J and Vreeland JR (2009) Democracy and dictatorship revisited. Public Choice 143(1-2), 67-101.

Chen MK (2013) The effect of language on economic behavior: evidence from savings rates, health behaviors, and retirement assets. American Economic Review 103(2), 690-731.

Chomsky N (1980) On binding. Linguistic Inquiry 11(1), 1-46.

Chung CO (1978) Pyongyang Between Peking and Moscow: North Korea's Involvement in the Sino-Soviet Dispute, 1958-1975. Tuscaloosa: University of Alabama Press.

Crystal J (1989) Coalitions in oil monarchies. Comparative Politics 21(4), 427-443.

Cupery D (2011) Buying Goodwill with Economic Exchange? Latin American Public Opinion and Elite Rhetoric toward the United States and China. PhD dissertation. Boulder: University of Colorado.

Fevziu B (2016) Enver Hoxha: The Iron Fist of Albania. London: I.B. Tauris.

Gandhi J (2008) Political Institutions Under Dictatorship. New York: Cambridge University Press.

Gandhi J and Przeworski A (2007) Authoritarian institutions and the survival of autocrats. Comparative Political Studies 40(11), 1279-1301.

Gandhi J and Sumner JL (2020) Measuring the consolidation of power in non-democracies. Journal of Politics 82(4), $1545-1558$.

Gebrekidan S (2020) For autocrats, and others, coronavirus is a chance to grab even more power. New York Times, 30 March.

Geddes B (1999) What Do We know about democratization after twenty years? Annual Review of Political Science 2, 115-144.

Geddes B, Wright J and Frantz E (2014) Autocratic breakdown and regime transitions: a new data set. Perspectives on Politics 12(2), 313-331.

Glazer A and Segendorff B (2005) Credit claiming. Economics of Governance 6(2), 125-137.

Greene KF (2007) Why Dominant Parties Lose: Mexico's Democratization in Comparative Perspective. New York: Cambridge University Press.

Grimmer J, Messing S and Westwood SJ (2012) The effect of legislator credit claiming on constituent credit allocation. American Political Science Review 106(4), 703-719.

Henisz WJ (2005) Political institutions and policy volatility. Economics and Politics 16(1), 1-27.

Hu Y and Liu AH (2020) The effects of foreign language proficiency on public attitudes. Journal of East Asian Studies 20(1), $1-23$.

Huang CTJ (1989) Pro-drop in Chinese: a generalized control theory. In Jaeggli OA and Safir KJ (eds), In the Null Subject Parameter. Dordrecht, the Netherlands: Springer, pp. 185-214.

Kenny PD (2020) 'The enemy of the people': populists and press freedom. Political Research Quarterly, 73(2), $261-275$.

Kim YK and Zagoria DS (1975) North Korea and the major powers. Asian Survey 15(12), 1017-1035. 
Kingsley P (2017) Erdogan claims vast powers in Turkey after narrow victory in referendum. New York Times, 16 April. Krishnan V (2020) The callousness of India's COVID-19 response. The Atlantic, 27 March.

Lai B and Slater D (2006) Domestic sources of dispute initiation in authoritarian regimes, 1950-1992. American Journal of Political Science 50(1), 113-126.

Levitsky S and Ziblatt D (2018) How Democracies Die. New York: Broadway Books.

Liu AH et al. (2018) Linguistic origins of gender equality and women's rights. Gender and Society 32(1), 1-27.

Liu AH (2021) Replication data for: Pronoun usage as a measure of personalization. https://doi.org/10.7910/DVN/FK6N8R, Harvard Dataverse, V1

Magaloni B (2006) Voting for Autocracy: Hegemonic Party Survival and Its Demise in Mexico. New York: Cambridge University Press.

Magyar B (2016) Post-Communist Mafia State. Budapest: Central European University Press.

Mayhew D (1974) Congress: The Electoral Connection. New Haven, CT: Yale University Press.

McCarthy J (2020) Concerns in the Philippines after Duterte given emergency powers to fight COVID-19 Spread. NPR, 24 March.

Meng A (2020) Constraining Dictatorship: From Personalized Rule to Institutionalized Regimes. New York: Cambridge University Press.

Na J and Choi I (2009) Culture and first-person pronouns. Personality and Social Psychology Bulletin 35(11), 1492-1499.

Pennebaker JW (2011a) The secret life of pronouns. New Scientist, 7 September.

Pennebaker JW (2011b) Your use of pronouns reveals your personality. Harvard Business Review.

Pennebaker JW et al. (2015) The development and psychometric properties of LIWC2015. Austin: University of Texas at Austin.

Pennebaker JW et al. (2014) When small words foretell academic success. PLoS ONE 9(12), e115844.

Pérez EO and Tavits M (2017) Language shapes people's time perspective and support for future-oriented policies. American Journal of Political Science 61(3), 715-727.

Rhodes-Purdy M and Madrid RL (2020) The perils of personalism. Democratization 27(2), 321-339.

Roth A (2020) Russian government quits as Putin plans to stay in power past 2024. The Guardian, 15 January.

Schuler P (2021) United Front: The Illusion of Deliberation in Vietnam's Single-Party Legislature. Palo Alto, CA: Stanford University Press.

Seligson MA (2007) The rise of populism and the left in Latin America. Journal of Democracy 18(3), 81-95.

Simmons RA, Gordon PC and Chambless DL (2005) Pronouns in marital interaction. Psychological Science 16(12), 932-936.

Simon D, Cook L and Clarke H (2018) Hungarian strongman's big victory poses headache for EU. CNN. http://www.cnn. com/2018/04/09/europe/hungary-viktor-orban-election-intl/index.html.

Slater D (2003) Iron cage in an iron fist. Comparative Politics 36(1), 81-101.

Spruyt B, Keppens G and Van Droogenbroeck F (2016) Who supports populism and what attracts people to it? Political Research Quarterly 69(2), 335-346.

Tharoor I (2020) Coronavirus kills its first democracy. Washington Post, 30 March.

Tulis JK (2017) The Rhetorical Presidency. Princeton, NJ: Princeton University Press.

Volden C (2005) Intergovernmental political competition in American federalism. American Journal of Political Science 49(2), 327-342.

Waisbord S (2011) Between support and confrontation: civic society, media reform, and populism in Latin America. Communication, Culture \& Critique 4(1), 97-117.

Wallace J (2018) Is Xi Jinping now a 'leader for life,' like Mao? Here's why this is dangerous. The Washington Post, 27 February.

Weeks JL (2012) Strongmen and straw men: authoritarian regimes and the initiation of international conflict. American Political Science Review 106(2), 326-347.

Weyland K (2001) Clarifying a contested concept: Populism in the study of Latin American politics. Comparative Politics 34(1), 1-22.

Windsor LC, Dowell N and Graesser A (2014) The language of autocrats: leaders' language in natural disaster crises. Risk, Hazards \& Crisis in Public Policy 5(4), 446-467.

Wright J (2008) Do authoritarian institutions constrain? How legislatures affect economic growth and investment. American Journal of Political Science 52(2), 322-343.

Wu CX and Wolford S (2018) Leaders, states, and reputations. Journal of Conflict Resolution 62(10), 2087-2117.

Cite this article: Liu AH (2022). Pronoun Usage as a Measure of Power Personalization: A General Theory with Evidence from the Chinese-Speaking World. British Journal of Political Science 52, 1258-1275. https://doi.org/10.1017/ S0007123421000181 